Journal of Educational Theory and Management https://ojs.s-p.sg/index.php/jetm

\title{
Place and Belonging: How Rural Primary School Principals can Promote Boarders' Development by Building their Sense of Belonging to School?
}

\section{Dan Cheng*}

Beijing Royal School, Beijing, 102209, China

\section{ARTICLE INFO}

Article history

Received: 1 June 2021

Revised: 10 June 2021

Accepted: 15 October 2021

Published Online: 30 October 2021

Keywords:

Rural borders

Sense of belonging to school

Principals

Students' development

\begin{abstract}
Rural boarding schools in compulsory education in China have proliferated with school merger program. This paper analyzes the relationship between school belonging and student development and the factors that influence students' sense of belonging in rural boarding schools. The paper examines how principals in rural boarding schools in China can promote student development by building a sense of belonging. The paper argues that building this sense of belonging can serve as a solution to the current problems affecting rural boarding schools, improve the quality of rural primary education, and promote student development.
\end{abstract}

\section{Introduction}

Boarding schools have long been recognised as an effective means of providing quality education for disadvantaged children ${ }^{[1,2]}$. More recently, the establishment of boarding schools, triggered by school consolidation programmes in rural China, has attracted increasing attention ${ }^{[3]}$. Since 2000, the number of students in China's rural schools has been rapidly declining due to mass rural-urban migration and the one-child policy ${ }^{[4]}$. To address these concerns, the Chinese State Council issued a document on basic education reform in $2001^{[5]}$, leading to the launch of a massive school consolidation programme in rural China, with the construction of rural boarding schools becoming one of the most critical projects in the programme. Primary boarding schools are expected to provide children with quality educational resources to compensate for the lack of family conditions, thus improving the quality of learning and life. However, the level of academic achievement and physical and mental development of boarding school students has not been as positive. This paper explores how headmasters in rural boarding schools in China can promote student development by building a sense of belonging. The paper argues that building this sense of belonging can be used as a solution to the current problems affecting rural boarding schools, improving the quality of rural primary education and promoting student development.

\section{Literature Review}

\subsection{Rural Boarding Schools in China}

Scholars stated that boarding school is an effective way of solving education problems in remote and mountainous

*Corresponding Author:

Dan Cheng,

Beijing Royal School, Beijing, 102209, China;

Email:531367172@qq.com 
areas due to the school merger program ${ }^{[6-8]}$. They believe that the construction of boarding schools will undoubtedly help improve the quality of rural education and the balanced development of urban and rural education in the long run ${ }^{[9]}$.

First, scholars argue that newly constructed boarding schools are equipped with better facilities and can maximize teaching resources in the classroom ${ }^{[7]}$. Further, teachers at consolidated schools have more resources to develop a better curriculum for students. Subject areas that are not traditionally focused, such as music, physical education, and art, can be taught by professional teachers ${ }^{[10]}$. In contrast, language and mathematics teachers used to teach these out-focus subjects on a part-time basis before the school's merger.

Second, scholars believe that boarding is conducive to the physical and psychological development of rural pupils. Boarding is beneficial in developing self-care skills. Students in rural boarding schools are mainly children left-behind by their parents who migrated to urban areas for higher earnings to send home and are often under the care of grandparents. Many of them lack necessary life skills. In boarding schools, students are taught and required to practice general life skills daily, such as making beds, doing laundry, and cleaning up by themselves ${ }^{[1]}$. Boarding also helps students develop interpersonal skills as they learn to form rudimentary social contracts and learn to observe common etiquette in shared spaces such as a dormitory ${ }^{[12]}$. These are important steps for developing interpersonal relationships and cooperation skills.

However, pupils in rural boarding schools are at a critical stage in their physical and psychological development, and long periods of boarding leave them without adequate family care and support. Research shows that boarding harms pupils' academic performance and physical and psychological development.

\section{A. Academic outcomes}

Mixed conclusions on the effect of boarding on students' academic performance were drawn in China, with the overall effect tilted towards the negative. A survey exploring the impact of boarding on minority students in rural primary schools shows that boarding students' scores on Chinese and mathematics were significantly higher than those of non-boarding students ${ }^{[13]}$. In contrast, Wang and Mao ${ }^{[14]}$ showed that boarders' scores on Chinese were significantly lower than those of non-boarders and that boarding had a significant adverse effect on the academic outcome of those boarders left behind by their parents. Mo et al. ${ }^{[3]} \quad$ also found that boarding had a negative impact on pupils' mathematics performance. Similarly, Guo et al. ${ }^{[4]}$ found a negative effect of school boarding on fourth-grade students' mathematics performance in a large sample in rural China. In 2016, a research team from Peking University (RTPU) used the International Reading Proficiency Test to evaluate primary boarding schools. The result showed that rural boarders' literacy skills are about one year behind the global average of 46 countries and regions. The study also showed that up to 16 percent of students reported that they failed to move onto the next grade because they could not pass the current one ${ }^{[15]}$.

\section{B. Psychological problems and bullying}

The merger of rural schools has led to a longer distance between home and school for some students. To save on travel costs, most students chose long periods of boarding. According to a survey ${ }^{[16]}$ conducted in three provinces in the central and western regions, $40 \%$ of students went home once a week while $37 \%$ did so every two weeks. There were also $3 \%$ of the students who reported to go home only once every one to two months. While most boarding schools provide a good learning environment, care outside of the study fell short for boarding students. According to Yang and Guo's survey ${ }^{[16]}$, the proportion of severely depressed students in rural primary boarding schools reaches as high as $65.7 \%$, with boarding students scoring much higher in psychological depression than their non-boarding counterparts. At the same time, bullying in boarding schools remains common. Children left behind are the primary victims of bullying in school, with $31.7 \%$ of victims reporting being bullied at least two to three times a month ${ }^{[15]}$. Younger boarding students (grades 1 and 2) are more likely to be bullied and to bully others (ibid.).

In summary, primary boarding schools are expected to provide children with better education and improved quality of life. However, the academic performance and the level of physical and psychological development of rural boarders showed that boarding schools have not lived up to the expectation. There is an urgent need to take adequate measures to address these issues, and one such measure is to improve boarders' sense of belonging to the school.

\subsection{Students' Sense of Belonging to Schools}

Belonging is considered one of the basic human needs. Belonging is a sense of being somewhere where you can be confident that you will fit in and be safe in your identity ${ }^{[17]}$, and a feeling of being at home in a place ${ }^{[18]}$. According to Goodenow, a sense of belonging for 
students is defined as a 'sense of being accepted, valued, included and encouraged by others (teacher and peers) in the academic classroom setting and of feeling oneself be an important part of the life and activity of the class ${ }^{[19]}$.

A few factors that are thought to increase students' sense of belonging to the school have been identified. These factors are consistent with many school practices and expectations ${ }^{[20]}$. Clement ${ }^{[20]}$ argues that students' sense of belonging to school is promoted through a whole-school approach that includes classroom and school climate. An overall positive school climate may positively impact students' ability to cope, form relationships, and manage their behaviors ${ }^{[20,21]}$. Both good relationships between peers ${ }^{[22]}$ and positive teacherstudent relationships have a strong impact on children's engagement and sense of belonging. The relationship between students and teachers is identified as the most important factor influencing children's sense of belonging to the school ${ }^{[23]}$. In addition, young people's relationships with other school staff are also meaningful ${ }^{[24]}$. Given these common factors, students' sense of belonging also varies across different school settings.

A sense of belonging to the school plays a crucial role in students' development, mainly related to their academic performance and wellbeing. Research suggests that a sense of belonging to school is positively related to students' academic achievement as students with a strong sense of belonging achieving better academic outcomes than those who do not ${ }^{[19]}$. A recent study ${ }^{[25]}$ suggests a strong link between children's physical and emotional 'safety' in school - an essential aspect of belonging and their academic performance in math and science. Abdollahi and Noltemeyer ${ }^{[26]}$ find that students with a stronger sense of belonging work harder to achieve their academic goals. Conversely, students with lower school belonging experience lower academic success, even though they have the knowledge and skills needed to perform better.

Researchers argue that there is also a strong association between belonging and other positive social outcomes, such as psychological health and physical wellbeing. Allen et al. ${ }^{[27]}$ argue that a sense of belonging positively impacts students' wellbeing, self-esteem, behavior, emotions, and social skills. Findings ${ }^{[26]}$ highlight that students' sense of belonging and psychological problems, such as depression and stress, are negatively correlated, i.e., the stronger a sense of belonging, the fewer psychological problems.

Further, students with a strong sense of belonging are more socially responsible and less likely to engage in absenteeism, violence, and bullying ${ }^{[28,29]}$. Students who feel a strong sense of belonging to their school evaluate themselves more positively and confidently, and are therefore more willing to help and support their peers ${ }^{[20]}$.

However, the effects of belonging may differ among students depending on their living environment. For example, a strong sense of school belonging can significantly lower drop-out rates, disruptive behavior, and substance and tobacco use for students from low and middle-income urban families ${ }^{[27]}$. Establishing a sense of belonging to a school is even more critical and challenging for boarding students. Long-term boarding at school replaces the home environment and makes the school the most important place in a young person's life ${ }^{[30]}$. A sense of belonging to school may help relieve feelings of loneliness away from home. As a result, feeling engaged at school is instrumental for boarders' academic and social success ${ }^{[14]}$.

\subsection{Place and Leadership of Place}

Place is both a physical reality and an emotional response to the world around us ${ }^{[31]}$. Place and belonging are inextricably linked. What makes a school a place where young people and adults want to go is whether physical and social spaces are transformed into places of belonging and learning ${ }^{[32]}$. Schools need to provide young people with 'safe and secure environments' where 'they can feel that they belong, ${ }^{[17]}$.

Schools are considered places that influence students' sense of belonging ${ }^{[2,23]}$ and engagement ${ }^{[33,21]}$. Schools can promote the spiritual, moral, social, and cultural development of children and young people. As a place maker, the principal should strive to make the school a place of belonging that promotes all members' acceptance and growth ${ }^{[24]}$. There are a few ways to achieve this. Firstly, the principal needs to have a range of knowledge and leadership strategies at their disposal that are central to students' sense of belonging, wellbeing, and agency. This helps make them believe that what they do can make a difference and that they have the capacity and opportunity to do so. Secondly, the principal should take a systematic approach in creating places that promote inclusion and place students at the heart of this process ${ }^{[17]}$. Finally, the principal must build trusting relationships with staff and students to ensure their needs are met.

\section{Factors that Affect Students' Belonging to the School}

Generally speaking, there are several factors that lead to the lack of a sense of belonging among boarding school students. First, rural boarding schools often lack sufficient funds to support their construction needs. Second, rural 
boarding schools often exert excessive academic pressure on students, which reduces important leisure time. Some also experience inadequate accommodation and insufficient school staffing, all of which negatively affect students' sense of belonging to the school.

\subsection{Inadequate Funding for Rural Boarding Schools}

Demand for rural boarding schools currently outweighs the State's investment in education. Although boarding schools reduce the overall cost of providing an education in the long term, the high construction cost can impede the short run. As a result, rural boarding schools require more financial support from the State compared to ordinary schools. Although rural boarding schools receive an allocation in China's education funding, there is still a severe shortage in funding, especially in more remote and poorer areas ${ }^{[34]}$. The shortage affects the construction and renovation of boarding schools and directly impacts the success in improving students' studying and living conditions ${ }^{[16]}$. A shortage of rural boarding school funding could indirectly lead to a reduced sense of belonging for students through lesser conditions.

\subsection{Excessive Academic Pressure on Students}

Studies on rural boarding schools show that long hours of study and rote learning lead to excessive stress, impacting students' sense of belonging to the school. Yang and Gao's research on boarding students in three provinces in central and western China show that many boarding schools not only extend classroom teaching hours but also increase the time for self-study in the morning and evening, with students studying for more than 9 hours throughout the day ${ }^{[16]}$. Subjects in rural primary boarding schools are inflexible. To receive higher scores on exams, some schools replaced P.E. and art classes with those on test subjects, and some even canceled extracurricular activities ${ }^{[35]}$. Students are physically and mentally exhausted from studies and examinations, which adversely affects their wellbeing and sense of belonging. Research ${ }^{[36]}$ shows that boarding students in the sixth grade in primary schools score the lowest in school belonging. This is due to the transition from primary to middle school, which carries the highest academic stress in primary school ${ }^{[37]}$.

\subsection{Lack of Extracurricular Activities}

Participating in extracurricular activities helps boarding students build strong relationships with their teachers and peers, which is conducive to forming a sense of belonging to the school. However, rural boarding students experience low-quality leisure time, as it is often squeezed by extra teaching hours, restricted by strict space management, and limited by a lack of activity planning and guidance.

One of the most notable problems in rural boarding schools is the poor allocation of study and leisure time, with the former frequently dominating the latter. Schools generally replace leisure activities with class hours to reduce risks and the associated liability to accidents. According to a 2008 survey conducted in the Guangxi Region and Hebei Province by the Central Institute of Education Science Research (CIESR), about $91.3 \%$ of students indicated that they would like to participate in their schools' extracurricular activities. However, only $27 \%$ of the schools organized activities regularly, and most of the schools did not meet students' demand for extracurricular activities ${ }^{[38]}$. In addition, rural boarding schools often manage students in lockdown style, severely restricting the space for activities. The lockdown style confines students to a small area on campus with limited or no exposure to the outside world, such as nature and the wider society. It affects the integrity of children's lives and suppresses their imagination and creativity ${ }^{[13]}$. Lastly, there is a lack of planning and practical guidance for extracurricular activities. Most schools let students chase and play on campus without supervision over their after-school activities, even less in the conscious design of activities ${ }^{[39]}$. A lack of general guidance for afterschool activities by specialized teachers also fails to meet students' diverse needs ${ }^{[35]}$.

\subsection{Inadequate accommodation in boarding schools}

Activities in dormitories and canteens play the role of family care in rural boarding schools ${ }^{[8]}$. However, conditions of dormitories and canteens in rural boarding schools tend to be severely inadequate and, as a result, cannot compensate for the lack of family functions for boarding students.

Dormitories in rural boarding schools are simple in design and cannot completely replace a sense of home. Dormitories are where students spend most of their time outside classrooms and should be a physical and psychological refuge for them. However, most rural boarding school dormitories only serve the most basic physical function, such as sleeping space for students ${ }^{[36]}$, and facilities are often in disrepair and overcrowded. According to a survey ${ }^{[4]}, 45 \%$ of rural boarders live in dormitories with 8-16 students per room, and 23\% live in dormitories with more than 16 students per room. Moreover, the dormitories look bare and are undecorated ${ }^{[15]}$, making it difficult for students to feel at home. In such 
an environment, students cannot feel relaxed to develop a sense of belonging.

Canteens at rural boarding schools often face challenges in providing nutritious meals for students. Ensuring normal physical development for rural boarding students should be the central task of the canteen. However, many rural school canteens fail to provide students with adequate nutritious food ${ }^{[40]}$. The management of canteens in many schools is still at the basic level of ensuring no one is hungry, with little consideration for nutritional values in the meals. According to a survey ${ }^{[3]}$ conducted on 144 primary schools in 10 counties in Shaanxi Province, principals do not recognize the importance of nutrition for students, with only $13 \%$ of them reporting to have some basic knowledge of nutrition and health ${ }^{[4]}$. Compared to those at home, meals in the canteen do not meet students' nutritional needs and preclude them from developing a sense of belonging as a result.

\subsection{Unqualified Caregivers}

As mentioned earlier, good relationships between students and staff on campus are an important aspect of fostering their sense of belonging. Rural boarding primary schools lack sufficient caretaking staff, making it difficult to provide students with emotional support while affecting their sense of belonging to the school.

First, there is a lack of caregivers in dormitories, leading to many teachers working as caregivers after class. However, teachers have limited energy after teaching, and devoting too much energy to caring for students may adversely affect their teaching quality ${ }^{[42]}$.

Second, caregivers are often under-educated and do not have the qualification to provide needed support. According to Guo ${ }^{[4]}, 67 \%$ of caregivers on campus have a junior high school education, $22 \%$ have a high school education, and $8 \%$ have only a primary school education. They act as general dormitory managers, whose job is mainly to take care of the physical environment and urge students to sleep on time ${ }^{[16]}$. They cannot provide emotional comfort or professional counseling to help students solve psychological and behavioral problems related to long-term boarding ${ }^{[43]}$, making it difficult for students to develop close emotional ties with them.

In short, in the absence of appropriate staffing, boarding students' school life is dominated by teachers who follow a learning-first strategy with activities organized around rote learning. It is difficult for students to develop a sense of belonging when full-time teachers dominate classroom and leisure time and neglect their physical and psychological development.

\section{Implications-leadership of Boarding School Principals}

Given funding shortfalls from government sources, principals from rural boarding schools have the ability at their disposal to foster students' sense of belonging as a way to improve their physical and psychological development and academic performance. This paper suggests the following ways for principals to foster such a sense of belonging based on the factors discussed prior.

\subsection{Improve Accommodation Conditions in Boarding Schools}

Since dormitories and canteens play a central role in boarding students' life after class, principals should first upgrade the schools' boarding and lodging conditions to encourage students' sense of belonging to the school. First, the principal should work to create a safe and relaxing environment in dormitories for pupils. For example, adding curtains to dormitories will make students feel safer and improve privacy ${ }^{[44]}$. Besides, dormitories should be decorated according to students' age and preference to create a relaxing environment ${ }^{[45]}$.

Second, the principal should raise awareness of nutrition in meals supplied by the campus canteens to ensure a balanced diet for all students and staff. The principal should maximize nutritional value for students within the limit of funding ${ }^{[4]}$. Secondly, nutrition training for rural teachers should be provided to ensure that teachers have basic nutrition knowledge to set up nutrition courses and activities. In addition to this, teachers should also guide students to focus on a balanced diet and be less picky about food ${ }^{[41]}$.

\subsection{Allocate Time for Study and Extracurricular Activities to Enhance of Boarders' Lives}

To improve students' sense of belonging to the school, it is necessary to properly allocate study and extracurricular time to ensure ample leisure time for students. Principals should invest more in facilities and provide guidance for extracurricular activities on the back of a trend away from test-oriented education.

Principals should realize the importance of extracurricular activities to students' development. Enriching students' leisure life means increasing afterclass activities and providing a suitable environment for well-rounded development for students. The activities can lead to enhanced friendships among students, creating a healthy community in boarding school life and helping them develop physically and mentally ${ }^{[30]}$. Principals should also increase investment in leisure facilities. 
Leisure infrastructures should be constructed to provide a safe and enriching environment for after-class activities ${ }^{[39]}$. Lastly, principals should focus on guiding leisure activities. Practical guidance plays an important role in enriching the spare time for boarding students. Only by equipping the school with highly qualified caregivers and conducting dormitory activities can students' leisure time be truly guaranteed and enhanced ${ }^{[39]}$.

\subsection{Improving Staffing and Clarifying the Division of Responsibilities}

Renovating the dormitory alone is not enough to foster a sense of belonging among boarders. Principals should also ensure that the school has an adequate number of professional caregivers, and the principal should preside over the development of specific responsibilities of the life teachers for students of different ages.

The number of staff in the dormitory should be proportional to the number of students to ensure they are adequately cared for. For example, primary boarding schools should have at least one supervisor for every 50 students ${ }^{[47]}$. The younger the students are, the more meticulous care they need. Therefore, the supervisor-tostudent ratio should be higher for a younger boarding population. For this reason, Shaanxi Province has stipulated that at least one supervisor is needed for every 20 students in grades 1 to 3 in primary schools ${ }^{[44]}$.

It is also important to ensure that the supervisor has the required expertise. Primary caregivers should take care of students' daily life and organize extracurricular activities for students and help them build a dormitory culture. Supervisors should be knowledgeable in education, psychology, primary hygiene, and epidemiology ${ }^{[45]}$. As it is unrealistic to recruit such high-quality supervisors in a short period given funding issues, it is more feasible to strengthen and improve the current training systems for working supervisors. Short-term intensive training for supervisors in professional knowledge and skills contributes to improved quality of life and level of physical development for boarding students ${ }^{[7]}$. Therefore, an effective and sustainable training program for supervisors can significantly benefit residential students' physical and psychological development.

Further, the specific responsibilities of supervisors for different age groups should be clearly defined. For younger boarding students, caregivers need to create a family atmosphere at the beginning to help alleviate homesickness and adjust to boarding life as soon as possible. For students in the upper grades, caregivers should focus on helping students develop good habits, and a sense of community ${ }^{[36]}$. Targeted parenting for students of different ages can compensate for the lack of family functions and enhance the students' sense of belonging to the boarding environment.

\section{Conclusions}

This paper explores how principals in rural boarding schools can improve students' development by fostering a sense of belonging to the school. Existing literature shows that rural boarding school students have relatively low academic performance and specific psychological and behavioral challenges. There is a strong relationship between students' academic performance, physical and psychological development, and their sense of school belonging. China's rural boarding schools have much to do to improve students' academic performance and promote physical and psychological development by enhancing a sense of belonging. The paper finds that the main factors that affect such a sense of belonging in rural primary boarding schools include financial and academic stress, lack of extracurricular activities, low-quality accommodation, and inadequate supervision. Lastly, this paper suggests that principals improve accommodation conditions, pay attention to school meal nutrition, and provide qualified caregivers to enhance students' sense of belonging and ultimately promote their personal development.

\section{References}

[1] Lee, B., and Barth, R.P.,. Residential education: An emerging resource for improving educational outcomes for youth in foster care?[J]. Children and Youth Services Review, 2009,31(1):155-160.

[2] Martin, A.J., Papworth, B., Ginns, P., and Liem, G.A.D.. Boarding school, academic motivation and engagement, and psychological wellbeing: A largescale investigation[J]. American Educational Research Journal,, 2014,51(5):1007-1049.

[3] Mo, D., Yi, H., Zhang, L., Shi, Y., Rozelle, S., and Medina, A.. Transfer paths and academic performance: The primary school merger program in Chi$\mathrm{na}[\mathrm{J}]$. International Journal of Educational Development, 2012,32(3): 423-431.

[4] Guo, S., Li, L., Sun, Y., Houang, R. and Schmidt, W.. Does boarding benefit the mathematics achievement of primary and middle school students? Evidence from China[J]. Asia Pacific Journal of Education, 2020:1-23.

[5] State Council, Decision of the State Council on the Reform and Development of Basic Education [EB/ OL], 2001. http://www.moe.edu.cn/edoas/wetsitel8/ 
info 3313.htm.

[6] Zeng F.. Analysis of unidirectional problems in rural boarding schools[J]. Economic Research Guide, 2019, No.33.

[7] Wang, Y.. Current situation and countermeasures for the development of boarding schools in rural northwest China[J]. New Silk Road, 2016, No.16: 96-99.

[8] Wang, J., Zhang, X.. A study of current problems in the development of rural compulsory education boarding schools in China[J]. Educational Science. 2010, No.3.

[9] Ma, F.. Bottlenecks and breakthroughs in the management of rural boarding schools in China[J]. Teaching and Management, 2018, No.3.

[10] Lan, Z., Li, S.. The Deep Contradiction and Balance of School Consolidation[J]. Teaching and Management,2017, No.3: 8-11.

[11] Liu X.. School Belonging and Social Support of pupils in Rural Areas: Based on Investigation of Primary Schools in Rural Areas of Luocheng Mulao Autonomous Country[J]. Journal of Hechi University, 2013, Vol.33, No.2.

[12] Liang, N., 2019. A study of school adaptation of younger boarding students in rural primary schools. Education Circle, No.20.

[13] Wu, N., Lian, H.. Review of research on the after-school life of students in rural boarding schools[J]. Journal of Hebei Normal University (Education Science Edition), 2017, No.12.

[14] Wang S., Mao Y.. The effect of boarding on campus on left-behind children's sense of school belonging and academic achievement: Chinese evidence from propensity score matching analysis[J]. Asia Pacific Journal of Education, 2018, Vol. 38, No. 3:378-393.

[15] The research team of Peking University (RTPU), Child Development Report for Rural Residential Schools[R], 2016. http://www.chinadevelopmentbrief.org.cn/news-18561.html.

[16] Yang, Z., Gao, P.. The problems, reasons and countermeasures of the students' adaption in rural boarding school in the compulsory education stage--Based on the investigation and analysis of 3 provinces regions in central and western regions[J]. Modern Education Management,2012, No.7.

[17] Riley, K..Place, belonging and school leadership: researching to make the difference[M]. London: Bloomsbury, 2017a.

[18] Yuval-Davis, N.. Belonging and the politics of belonging[J]. Patterns of Prejudice, 2006, 40(3): 197214.

[19] Goodenow, C., Grady, K. E.. The relationship of school belonging and friends' values to academic motivation among urban adolescent students $[\mathrm{J}]$. Journal of Experimental Education,1993, 62(1): 6071.

[20] Clement, N.. Students Wellbeing at School: The Actualization of Values in Education[C], International research Handbook on Values Eductaion and Student Wellbeing. Springer, Dordrecht,2010:37-62.

[21] Johnson, M. K., Crosnoe, R., Elder, G. H.. Students' attachment and academic engagement: The role of race and ethnicity[J]. Sociology of Education, 2001, No.74: 318-40.

[22] Furrer, C., and Skinner, E.. Sense of relatedness as a factor in children's academic engagement and performance[J]. Journal of Educational Psychology, 2001, 95(1):148-162.

[23] OECD. Leadership for 21st Century Learning, Centre for Educational Research and Innovation, Paris: Organisation for Economic Development and Cooperation, 2013.

[24] Riley, K.. We're a long way from a sense of belonging[N]. Times Educational Supplement. 2019, 7th June.

[25] International Association for the Evaluation of Educational Achievement. Do both boys and girls feel safe at school and does it matter?[C]. IEA Compass Briefs in Education. Amsterdam: International Association for the Evaluation of Educational Achievement. 2019, 5 February.

[26] Abdollahi, A., and Noltemeyer, A.. Academic hardiness: Mediator between sense of belonging to school and academic achievement?[J].The journal of educational research,2018, 111(3): 345-351.

[27] Allen K. A., Kern, P.. Boosting school belonging: Practical strategies to help adolescents feel like they belong at school[M]. Routedge: Oxon,2020.

[28] Anderman, E. M.. School effects on psychological outcomes during adolescence. Journal of Educational Psychology, 2002, 94(4):795-809.

[29] Osterman, K. F.. Students' need for belonging in the school community[J]. Review of Educational Research, 2000,70(3): 323-367.

[30] Yao, Z.. Reflections on Enriching the Life of Rural Boarding Schools[J]. Journal of Northeast Normal University (Philosophy and Social Science Edition), 2011, No.3.

[31] Riley, K.. Agency and belonging: What transformative actions can schools take to help create a sense of place and belonging?[J]. Educational and Child Psychology, 2019, Vol. 36, No. 4.

[32] Riley, K., Coates, M., and Martinez, S. P., 2018. 
Place and belonging in schools: Unlocking Possibilities[J]. London: UCL Institute of Education. www. ucl.ac.uk/ioe/department-centres/centres/london-centre-for-leadership-in-learning.

[33] Bryk, A.S., Thum, Y. M.. The effects of high school organization on dropping out: An exploratory investigation[J]. American Education Research Journal, 1989, 26(3): 353-83.

[34] Xu, L., Yuan, G.. Survey on the current situation of rural education resource allocation and optimization countermeasures[J]. Research on Education Development, 2006, No.6A: 57-62.

[35] Lin, X.. Research on the current situation and measures of after-school life of students in rural boarding schools - An investigation based on Minle County, Gansu Province. Exam Weekly.2012, No.10.

[36] Dong, S..Study on Boarding problems of rural Chi$\mathrm{na}[\mathrm{D}]$, Doctoral Thesis, Huazhong Normal University, 2012.

[37] Su F., Chen L., Yang Q.. Analysis of factors affecting the school belonging of elementary students in rural[J]. Community Medicine Journal, 2018,Vol.16, No.8.

[38] Central Institute of Education Science Research. Study on the management of after-school life of students in rural boarding schools in poor areas-Based on the research in Du'an County[J], Guangxi Zhuang Autonomous Region and Fengning County, Hebei Province. Education Research, 2018, No.4.
[39] Zhang, B.. Reflections on after-school activity arrangements in boarding primary and secondary schools[J]. Innovative Education, 2011, No.10.

[40] Li, W.. Evaluating the effectiveness of a nutritional feeding program for boarding students in poor areas[J]. Agricultural Technology and Economy, 2011, No.6.

[41] Liao, W.. Nutritional status of students in rural boarding schools in China[J]. School health in China, 2011, No.9.

[42] Zhai, Y.. Problems of life teachers in rural boarding schools in China and analysis of their causes[J]. Theory of Learning, 2011, No.7.

[43] Zhao, Y., Liu, X.. Mental health education for primary school students in pastoral boarding schools[J] Quality Education,2015, No.3.

[44] Geluying. Rural Boarding School Student Development Report[R],2016, http://www.growinghome.org. cn/news_show/68.html.

[45] Tang, J.. Effective measures to strengthen the management of rural primary boarding schools. Development, 2020, No.1.

[46] Yu, Y., Huang, Y.. Improving children's nutrition from rural boarding schools[J]. Education in Guangxi, 2009 No.6.

[47] Ministry of Education, 2011. http://www.moe. gov.cn/srcsite/A17/moe_943/moe_948/201108/ t20110816 124983.html. 